\title{
Attenuated amyloid- $\beta$ aggregation and neurotoxicity owing to methionine oxidation
}

\author{
Ann-Sofi Johansson ${ }^{\mathrm{a}}$, Jonas Bergquist ${ }^{\mathrm{b}}$, Christiane Volbracht ${ }^{\mathrm{d}}$, Anna Päiviö ${ }^{\mathrm{c}}$, Marcel Leist ${ }^{\mathrm{d}, \mathrm{e}}$, \\ Lars Lannfelt ${ }^{\mathrm{a}}$ and Anita Westlind-Danielsson ${ }^{\mathrm{d}}$

\begin{abstract}
${ }^{a}$ Department of Public Health and Caring Sciences, Uppsala University, Uppsala, Sweden, ${ }^{b}$ Department of Physical and Analytical Chemistry/Analytical Chemistry, Uppsala University, Uppsala, Sweden, 'Department of NEUROTEC, Karolinska Institutet, Huddinge, Sweden, ${ }^{d}$ Disease Biology, Drug Discovery Unit, H. Lundbeck A/S Valby, Denmark and eUniversity of Konstanz,
\end{abstract} \\ Konstanz, Germany
}

\begin{abstract}
Aggregation of the amyloid- $\beta(A \beta)$ peptide into amyloid plaques is a characteristic feature of Alzheimer's disease neuropathogenesis. We and others have previously demonstrated delayed $A \beta$ aggregation as a consequence of oxidizing a single methionine residue at position 35 (Met-35). Here, we examined the consequences of Met-35 oxidation on the extremely aggregation-prone peptides $A \beta \mid-42$ and $A \beta \mid-40 A r c t i c$ with respect to protofibril and oligomer formation as well as neurotoxicity. Size exclusion chromatography and mass spectrometry demonstrated that monomer/dimers
\end{abstract}

prevailed over larger oligomers after oxidizing Met-35, and consequently protofibril formation and aggregation of both $\mathrm{A} \beta \mathrm{I}-42$ and $A \beta I-40 A$ rctic were delayed. The oxidized peptides completely lacked neurotoxic effects in cortical neuronal cultures under these conditions, in contrast to the neurotoxic properties of the unoxidized peptides. We conclude that oxidation of Met-35 significantly attenuates aggregation of $\mathrm{A} \beta \mathrm{I}-42$ and $\mathrm{A} \beta \mathrm{I}-40 \mathrm{Arctic}$, and thereby reduces neurotoxicity. NeuroReport 18:559-563 (C) 2007 Lippincott Williams \& Wilkins.

\section{Introduction}

Soluble amyloid- $\beta$ (A $\beta$ ) oligomers are currently suspected to be the major neuropathogens active in Alzheimer's disease (AD) $[1,2]$. Cognitive decline has been correlated with cerebral levels of soluble $\mathrm{A} \beta$ in $\mathrm{AD}$ patients [2] and neurotoxic properties have been attributed to small $\mathrm{A} \beta$ oligomers [3] as well as larger oligomers, that is protofibrils [4].

Whether monomeric $A \beta$ induces neurotoxicity is not unambiguous, largely because of the technical difficulties in preparing pure monomeric $A \beta$ solutions at relevant concentrations and maintaining them in a cell culture environment. For instance, the literature is conflicting on whether low molecular weight $A \beta$ (a preparation consisting largely of monomers and possibly smaller oligomers [5]) is nontoxic [6] or toxic [4].

We have demonstrated previously that oxidation of the single methionine residue at position 35 (Met-35) attenuates A 1 1-40 trimer formation. This finding provides us with a useful tool to evaluate the neurotoxicity of low molecular weight $A \beta$ primarily consisting of monomers and dimers. Therefore, we compared the aggregation and neurotoxic properties of $A \beta 1-42$ and A $\beta 1-40$ Arctic (E22G) in their reduced and oxidized form. The latter peptide is produced by carriers of the Arctic amyloid precursor protein mutation, and spontaneously generates high levels of protofibrils in vitro [1].

\begin{abstract}
Methods
$\beta$-Amyloid peptides and reagents

Synthetic A $\beta$ peptides were purchased from Biosource (Camarillo, California, USA). For the size exclusion chromatography (SEC) experiments, $A \beta 1-42$ and A $\beta 1-40$ Arctic peptides were Met-35 oxidized according to our previously published protocols using $2.7 \% \quad \mathrm{H}_{2} \mathrm{O}_{2}$ [7]. For all other experiments, oxidized A $\beta$ Met-35 was purchased from Biosource where oxidation had been carried out using dimethylsulfoxide. All Met-35 oxidized and unoxidized peptides were checked for their correct identity by sequence analysis, and mass determination using mass spectrometry. All reagents and antibodies were purchased from SigmaAldrich (St. Louis, Missouri, USA), unless otherwise stated.
\end{abstract}

\section{Animals}

Timed-pregnant-specific pathogen-free $\mathrm{C} 57 \mathrm{Bl} / 6$ mice were purchased from Harlan (Horst, Netherlands). All experiments were performed in accordance with international guidelines to minimize pain and discomfort (NIH-guidelines) and European Community Council Directive 86/609/EEC.

Kinetics of protofibril formation with size exclusion chromatography (SEC)

A $11-40$ Arctic was dissolved in cold $\mathrm{H}_{2} \mathrm{O}$, and diluted with an equal volume $2 \times$ phosphate-buffered saline (final 
concentration: $0.05 \mathrm{M}$ phosphate buffer, $\mathrm{pH} 7.4,0.10 \mathrm{M}$ $\mathrm{NaCl}$ ). A $\beta 1-42$ was dissolved in 1/10 dimethylsulfoxide before ice-cold $\mathrm{H}_{2} \mathrm{O}$ was added. Before SEC analysis peptide samples were incubated for different time intervals using a static kinetic incubation protocol at $30^{\circ} \mathrm{C}$. Samples were centrifuged at $17900 \mathrm{~g}$ for $5 \mathrm{~min}$ at $16^{\circ} \mathrm{C}$ and the supernatant analyzed on a Merck Hitachi D-7000 HPLC LaChrom system with UV detection using a Superdex 75 PC3.2/30 column (Amersham Biosciences, Uppsala, Sweden) as described earlier [1].

\section{Mass spectrometry}

All mass spectra were acquired using a Bruker Daltonics (Billerica, Massachusetts, USA) BioAPEX-94e superconducting 9.4 T Fourier transform ion cyclotron resonance electrospray mass spectrometer (FTICR-MS) as earlier described in Palmblad et al. [7]. Peptides were dissolved in either double distilled $\mathrm{H}_{2} \mathrm{O}$ or in acetonitrile: $\mathrm{H}_{2} \mathrm{O}(50: 49)$ with $1 \%$ acetic acid.

\section{Cell culture and treatment}

Murine cortical neurons were isolated from day 14-16 fetal C57Bl/6 mice as described previously [8]. Dissociated neurons were plated on $100 \mu \mathrm{g} / \mathrm{ml}$ poly-D-lysine coated dishes at a density of about $0.25 \times 10^{6}$ cells $/ \mathrm{cm}^{2}$ and cultured in Neurobasal (Invitrogen, San Diego, California, USA) supplemented with $2 \%$ B-27 supplement without antioxidants (Invitrogen), $0.5 \mathrm{mM}$ L-glutamine, $100 \mathrm{U} / \mathrm{ml}$ penicillin and $0.1 \mathrm{mg} / \mathrm{ml}$ streptomycin. Neurons were fed every third day by replacing half of the medium. Neuronal cultures were exposed to $A \beta$ peptides at 7 days of culture in vitro in their own medium. Before addition to the cortical cultures A $\beta 1-42$ peptides were dissolved in the same manner as for the SEC experiments. Potential aggregates were removed using a $5 \mathrm{~min}$ centrifugation at $20000 \mathrm{~g}$ $\left(16^{\circ} \mathrm{C}\right)$. The supernatants were used as the $\mathrm{A} \beta$ peptide source either directly or once these had been aged at $30^{\circ} \mathrm{C}$ for $24 \mathrm{~h}$.

\section{Neuronal toxicity}

Plasma membrane integrity and nuclear morphology were assessed by double-staining cortical cultures with the nuclear dyes H-33342 (cell permeant, blue fluorescent) and SYTOX (non cell permeant, green fluorescent) and counting of neuronal condensed nuclei. About 300 cells were counted in three different fields in three different culture wells, and experiments were repeated using at least three different preparations. In addition, the percentage of viable cells was quantified by their capacity to reduce 3-(4,5-dimethylthiazole-2-yl)-2,5-diphenyltetrasodium bromide (MTT) after incubation with $0.5 \mathrm{mg} / \mathrm{ml} \mathrm{MTT}$ for $60 \mathrm{~min}$.

\section{Immunofluorescence}

After desired period of treatment, cells were fixed in $4 \%$ paraformaldehyde. To monitor cytoskeletal alterations, we stained neurons with an anti- $\beta$-III-tubulin monoclonal antibody (1:300, \#clone5G8; Promega, Mannheim, Germany), which recognizes only neuronal tubulin. Anti-mouse IgG antibody conjugated with Alexa Fluor 488 (Molecular Probes) was used as the secondary antibody. Nuclei were counterstained with propidium iodide.

\section{Results}

A $\beta$ oxidation delays oligomer and protofibril formation Protofibril and monomer content for A $\beta 1-40$ Arctic and A $\beta 1-42$ as well as their Met-35 oxidized forms was assessed by SEC. Protofibrils are defined as the species eluting in the void volume of the column after sedimentation of fibrils and larger aggregates. The gel included peak is denoted monomer for clarity, but most likely contains some dimers and trimers as well. Monomeric levels of both unoxidized peptides disappeared rapidly while protofibrils were formed in parallel. In contrast to the unoxidized peptides, Met-35 oxidized peptides remained monomeric and produced barely detectable levels of protofibrils (Fig. 1) for up to $66 \mathrm{~h}$ of incubation (data not shown). To determine the proportions of monomers and small oligomers, samples of both $A \beta 1-40$ Arctic and A $\beta 1-42$ as well as their oxidized forms were analyzed at different time points using FTICRMS. The two unoxidized peptides contained low amounts of monomers, dimers, trimers and tetramers which disappeared after 7-8 h, likely owing to oligomerization (Table 1). The same phenomenon was observed at 100 to 1000 -fold lower concentrations $(1 \mu \mathrm{M}$ and $100 \mu \mathrm{M})$, however with much lower signals (data not shown). In contrast, a strong monomer signal was evident for both oxidized $A \beta$ peptides for up to $8 \mathrm{~h}$ of incubation (Table 1) and even up to $165 \mathrm{~h}$ (data not shown). Some dimers, but no trimers, were detected for both oxidized peptides, indicating delayed trimer formation. Our results by SEC and FTICR-MS demonstrate that Met-35 oxidation of A $11-40$ Arctic and $A \beta 1-42$ attenuates $A \beta$ oligomerization and hence protofibril formation.

\section{A $\beta$ oxidation abolishes neurotoxicity}

Making use of our finding that Met-35 oxidation attenuated the formation of $A \beta$ oligomers and protofibrils, we evaluated whether Met-35 oxidized peptides still induced neuronal death. Cortical neuronal cultures were exposed to various concentrations of unoxidized and oxidized A $\beta 1$ 40Arctic and A $\beta 1-42$ either given directly or pre-aged for $24 \mathrm{~h}$. Both peptide preparations (fresh or aged peptide) resulted in similar data. A $\beta 1-40$ Arctic caused cell death in cortical cultures in a concentration range of $10-40 \mu \mathrm{M}$ (Fig. 2). Toxicity was evident after $24 \mathrm{~h}$, and further increased at $48 \mathrm{~h}$ as measured by counting of dead neurons (Fig. 2a) and lost capacity to reduce MTT (Fig. 2b). Neurons displayed classical morphological characteristics of apoptosis including shrunken nuclei with chromatin condensation and fragmentation (Fig. 3b, right panel). A $\beta 1-42$ caused cell death of cortical neurons in a concentration range of 20-40 $\mu \mathrm{M}$ (Fig. 2). A $\beta 1-42$ toxicity was evident after $48 \mathrm{~h}$ and increased at $72 \mathrm{~h}$. In contrast to A $\beta 1-40$ Arctic, A $\beta 1-42$ triggered pyknotic/apoptosis-like morphological characteristics including shrunken nuclei with partially condensed, but not fragmented chromatin clumps (Fig. 3b, left panel). The oxidized peptides did not trigger any signs of cell death in the concentration range and incubation time sufficient for the deleterious effects of the unoxidized analogs (Fig. 2).

A well-known feature of AD is cytoskeletal alterations. We therefore examined whether treatment with unoxidized and oxidized $A \beta$ would lead to a disruption of the neuronal microtubule network (Fig. 3). The first alterations became apparent $24-36 \mathrm{~h}$ after exposure to unoxidized $A \beta$ peptides and after $48-72 \mathrm{~h}$ the microtubule network was completely 
lost, leaving only small dots surrounding the nucleus (Fig. $3 a$ and b). In contrast, oxidized $A \beta$ (Fig. 3a, lower panel) did not compromise the neurite network, which was indistinguishable from that of untreated cultures (Fig. 3b, middle panel).

\section{Discussion}

We have demonstrated that oxidation of a single methionine residue drastically changes the conformational fate of two aggregation-prone $A \beta$ peptides in such a way that aggregation is considerably attenuated. This has previously been observed for the much less aggregation prone wild type A $\beta 1-40$ peptide $[7,9]$, and recently also for $A \beta 1-42$ [10].
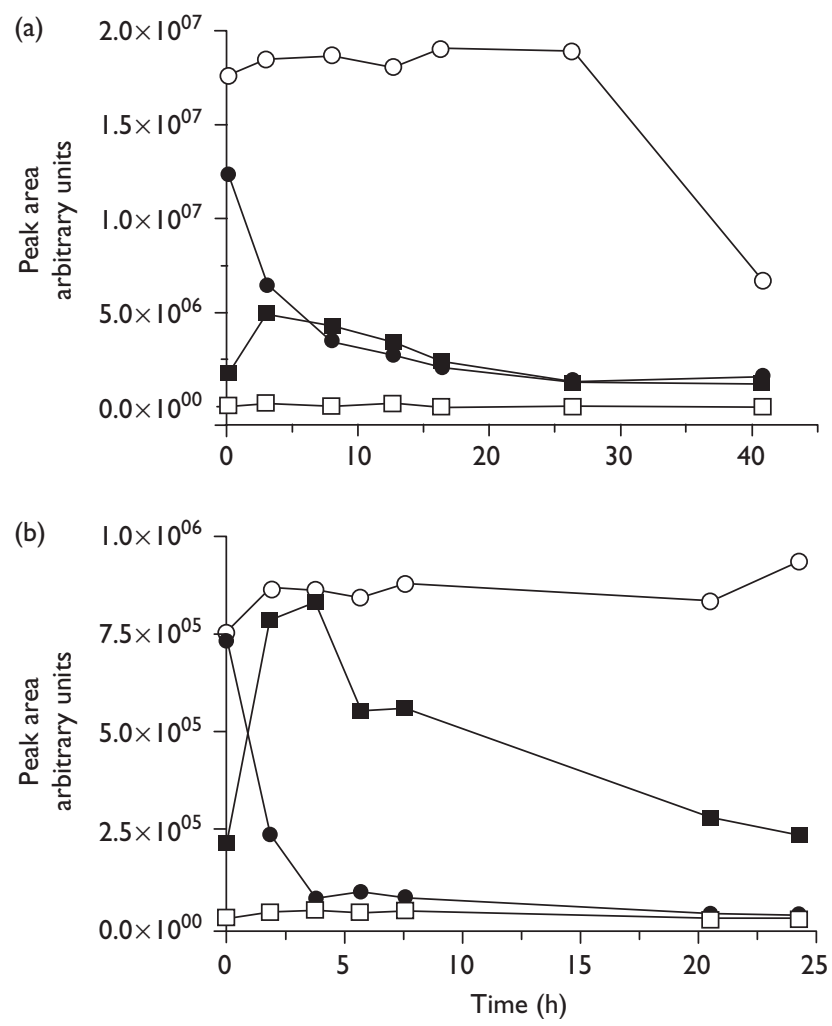

Fig. I Oxidation of A $\beta$ Met-35 delays protofibril formation. Aggregation kinetics of oxidized and unoxidized $A \beta \mathrm{I}-40$ Arctic and $A \beta \mathrm{I}-42$ were studied by SEC. A $\beta$ monomer and protofibril peak areas were plotted as a function of $A \beta$ incubation time. (a) $100 \mu \mathrm{M} A \beta I-40 A$ rctic in phosphatebuffered saline (b) $10 \mu \mathrm{M} \mathrm{A} \beta \mathrm{I}-42$ in 10\% dimethylsulfoxide (DMSO). Filled circles: unoxidized monomer, open circles: oxidized monomer, filled squares: unoxidized protofibrils, open squares: oxidized protofibrils. One experiment representative of three.
These previous observations are here extended by demonstrating both delayed oligomer and protofibril formation for Met-35 oxidized A $\beta 1-42$ as well as A $\beta 1-40$ Arctic. Trimer formation seemed to be attenuated also for these highly aggregating $A \beta$ peptides, similarly to what has previously been shown for A $\beta 1-40$ [7]. Moreover, we have demonstrated that these oxidized $A \beta$ peptides completely lost their neurotoxic capacity, supposedly because of the decreased production of $A \beta$ oligomers.

It has previously been proposed that $A \beta$ Met-35 plays a critical role in neurotoxicity. Substitution of Met-35 in A $\beta$ [11-13] and studies of $A \beta$ fragments lacking Met-35 [14,15] have demonstrated an attenuated ability for $\mathrm{A} \beta$ to exert oxidative stress and cytotoxicity. Recent studies comparing the toxic actions of Met-35 oxidized $A \beta$ and unoxidized $A \beta$ on isolated rat brain mitochondria [16] and human neuroblastoma cells [13] showed attenuated toxicity for the oxidized form. One suggestion for the mechanism behind these observations is that the Met- 35 residue plays a critical role as a mediator of oxidative stress [14], as substitution of Met-35 [11] or studies of $A \beta$ fragments lacking Met-35 [14,15] have shown attenuated ability to exert oxidative stress as well as neurotoxicity. Another possibility, although not thoroughly investigated, is that Met-35 oxidation prevents apoptosis, as Met-35 oxidation has been described to prevent the A $\beta 1-42$-mediated down regulation of the antiapoptotic gene $b c l-2$ [13]. Our findings support the view that oxidation of Met-35 renders $A \beta$ less neurotoxic by altering production of toxic $A \beta$ oligomers, oligomers that are claimed to have a range of unwanted, deleterious effects on neurons, including oxidative stress [17] and apoptosis [18]. Thus, attenuated ability of Met-35 oxidized $A \beta$ to exert oxidative stress and apoptotic events might be secondary effects to the altered aggregation behavior of this peptide.

A $\beta$ Met-35 may be oxidized in AD brains through exposure to free radicals produced and released by microglia, such as superoxide, which quickly forms reactive hydrogen peroxide [19]. In concert, the association of microglia with $\mathrm{A} \beta$ plaques is one hallmark of $\mathrm{AD}$ neuropathology [20]. In addition, the proportion of methionine sulfoxide could increase through decreased activity of methionine sulfoxide reductase, which reduces methionine sulfoxide back to methionine. Interestingly, Gabbita et al. (1999) have reported a decline in methionine sulfoxide reductase in brains of $A D$ patients [21]. We propose that $A \beta$ Met-35 oxidation may constitute a means by which $A \beta$ is rendered less toxic in the brain, if oxidation of Met- 35 occurs in situ to a significant extent. One may speculate how increased levels of Met- 35 oxidized $A \beta$ could be beneficial in AD: (i) build-up of toxic oligomeric species may be delayed;

Table I Observed oligomeric $A \beta$ species for oxidized [Met35(O)] and unoxidized A $\beta$ I-40Arctic and A $\beta$ I-42

\begin{tabular}{|c|c|c|c|c|c|c|c|c|}
\hline \multirow[b]{2}{*}{ Observed form } & \multicolumn{2}{|c|}{$A \beta I-42$} & \multicolumn{2}{|c|}{$\mathrm{A} \beta \mathrm{I}-42 \mathrm{Met} 35(\mathrm{O})$} & \multicolumn{2}{|c|}{ A $\beta \mathrm{I}-40$ Arctic } & \multicolumn{2}{|c|}{$\mathrm{A} \beta \mathrm{I}-40 \mathrm{Arctic} \operatorname{Met} 35(\mathrm{O})$} \\
\hline & $t=0$ & $t=8$ & $t=0$ & $t=8$ & $t=0$ & $t=8$ & $t=0$ & $t=8$ \\
\hline $\begin{array}{l}\text { Monomer } \\
\text { Dimer }\end{array}$ & $\begin{array}{c}+ \\
(+)\end{array}$ & $\begin{array}{c}(+) \\
-\end{array}$ & $\begin{array}{c}+++ \\
+\end{array}$ & $\begin{array}{c}+++ \\
++\end{array}$ & $\begin{array}{c}++ \\
+\end{array}$ & $\begin{array}{l}(+) \\
(+)\end{array}$ & $\begin{array}{c}+++ \\
(+)\end{array}$ & $\begin{array}{c}+++ \\
+\end{array}$ \\
\hline Trimer & $(+)$ & - & - & - & + & - & - & - \\
\hline Tetramer & $(+)$ & - & - & - & + & - & - & - \\
\hline
\end{tabular}

Oligomeric species measured by electrospray mass spectrometry after incubation of $100 \mu \mathrm{MA} \beta$ for 0 and $8 \mathrm{~h}$ at room temperature. The number of + signs reflects the intensity of the signal. 

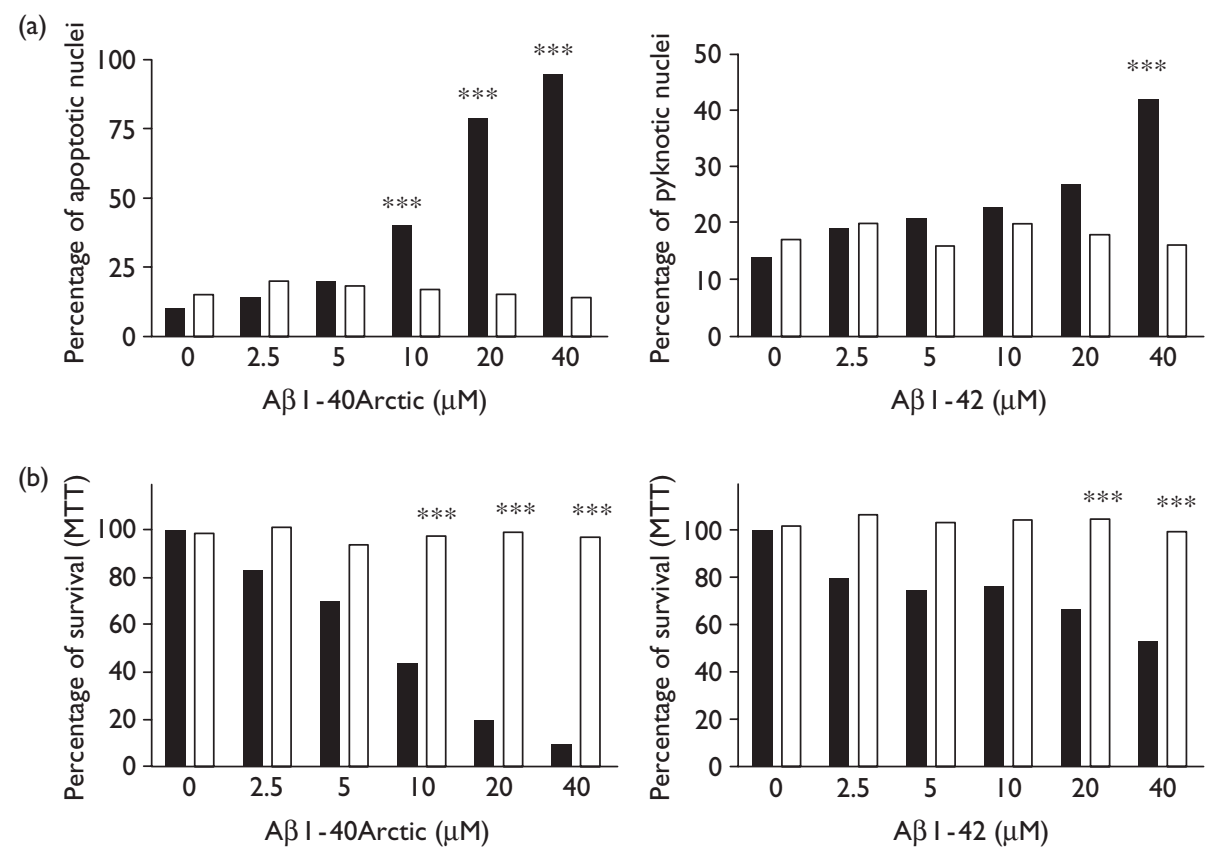

Fig. 2 Attenuated neurotoxicity following oxidation of $A \beta$ Met-35. Cortical neurons were incubated with oxidized or unoxidized A $\beta$ I-40Arctic and $\mathrm{A} \beta \mathrm{I}-42$ for 48 and $72 \mathrm{~h}$, respectively. (a) Neurons were stained with SYTOX and H-33342, and the percentage of condensed (apoptotic or pyknotic) nuclei was counted. (b) Cell survival was assessed using the 3-(4,5-dimethylthiazole-2-yl)-2,5-diphenyltetrasodium bromide (MTT) assay. Filled bars: unoxidized $A \beta$, open bars: oxidized $A \beta$, data are means \pm SD of triplicate determinations from three experiments. Significance was determined using one-way analysis of variance followed by the Tukey's test; ***P<0.00l.
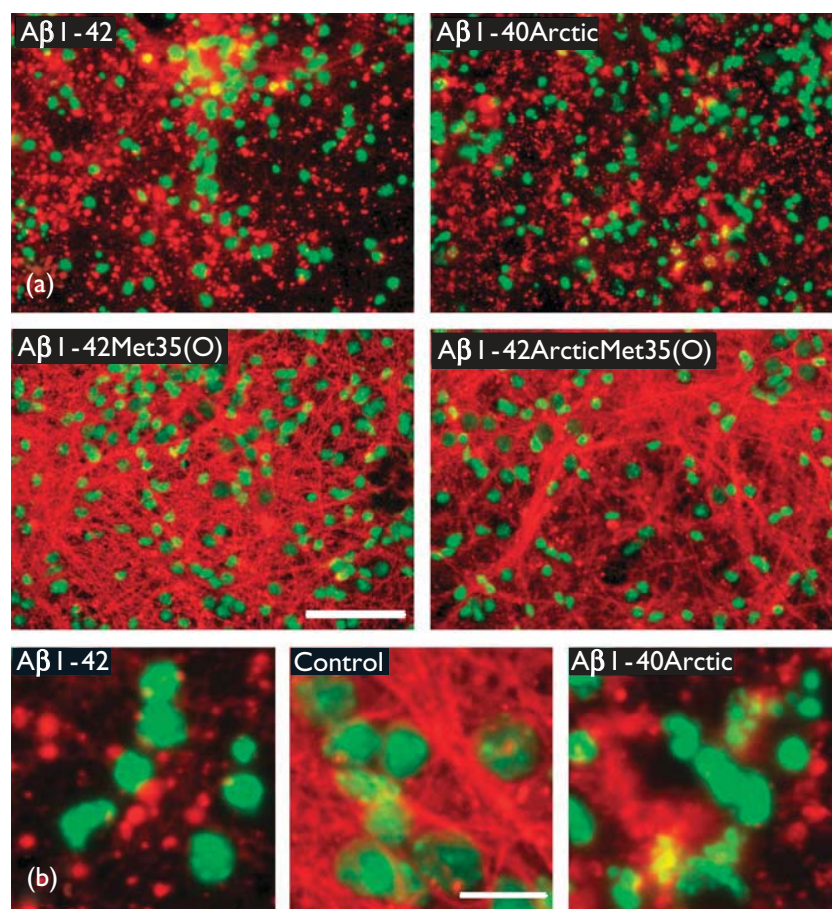

Fig. 3 Oxidation of $A \beta$ Met-35 prevents microtubule disruption in neurons. Cortical cultures were either treated with $20 \mu \mathrm{M}$ A $\beta$ I-40Arctic for $48 \mathrm{~h}$ or $40 \mu \mathrm{M} \mathrm{A} \beta \mathrm{I}-42$ for $72 \mathrm{~h}$ or untreated (control). Cells were fixed and stained for $\beta$-III-tubulin and chromatin (propidium iodide). Green channel: nuclei. Red channel: axodendritic network. (a) Low magnification images of unoxidized and oxidized $A \beta I-40 A r c t i c$ and $A \beta I-42$. Scale bar $=80 \mu \mathrm{m}$ (b) Note different nuclear morphology of $A \beta \mathrm{I}-40$ Arctic and $A \beta \mathrm{I}-42$ treated neurons: condensed and fragmented nuclei (apoptotic) versus shrunken nuclei (pyknotic). Scale bar $=15 \mu \mathrm{m}$. (ii) delaying oligomerization may allow for more substantial proteolytic processing of $\mathrm{A} \beta$, perhaps also by the $20 \mathrm{~S}$ proteasome [22]; (iii) the potentially neurotoxic interaction of oxidized $A \beta$ with cellular membranes could be compromised owing to the decreased hydrophobicity of methionine sulfoxide.

\section{Conclusion}

Posttranslational modification of Met-35 to a methioninesulfoxide in aggressively aggregating $A \beta$ peptides attenuates oligomerization and reduces neurotoxicity. We propose that $\mathrm{A} \beta$ Met-35 oxidation could be an example of an oxidative process that works in an advantageous direction to delay on-set and/or slow down progression of AD.

\section{Acknowledgements}

This work was supported by grants from EU Consortiums DIADEM and APOPIS, the Swedish Research Council (project no. 2003-5546 and 629-2002-6821), Hjärnfonden and Bertil Hållstens forskningsstiftelse, Alzheimerfonden, Stiftelsen Gamla Tjänarinnor, Stohnes stiftelse and Mary, Åke och Hans Ländells stiftelse.

\section{References}

1. Nilsberth C, Westlind-Danielsson A, Eckman CB, Condron MM, Axelman K, Forsell C, et al. The 'Arctic' APP mutation (E693G) causes Alzheimer's disease by enhanced Abeta protofibril formation. Nat Neurosci 2001; 4:887-893.

2. Terry RD, Masliah E, Salmon DP, Butters N, DeTeresa R, Hill R, et al. Physical basis of cognitive alterations in Alzheimer's disease: synapse loss is the major correlate of cognitive impairment. Ann Neurol 1991; 30:572-580. 
3. Klein WL. ADDLs \& protofibrils-the missing links? Neurobiol Aging 2002; 23:231-235.

4. Hartley DM, Walsh DM, Ye CP, Diehl T, Vasquez S, Vassilev PM, et al Protofibrillar intermediates of amyloid beta-protein induce acute electrophysiological changes and progressive neurotoxicity in cortical neurons. J Neurosci 1999; 19:8876-8884.

5. Bitan G, Teplow DB. Preparation of aggregate-free, low molecular weight amyloid-beta for assembly and toxicity assays. Methods Mol Biol 2005; 299:3-9.

6. Walsh DM, Hartley DM, Kusumoto Y, Fezoui Y, Condron MM, Lomakin A et al. Amyloid beta-protein fibrillogenesis. Structure and biological activity of protofibrillar intermediates. JBC 1999; 274:25945-25952.

7. Palmblad M, Westlind-Danielsson A, Bergquist J. Oxidation of methionine 35 attenuates formation of amyloid beta-peptide 1-40 oligomers. J Biol Chem 2002; 277:19506-19510.

8. Hertz E, Yu ACH, Hertz L, Juurlink BHJ, Schousboe A. Preparation of primary cultures of mouse cortical neurons. In: Shahar A, De Vellis J, Vernadakis A, Haber B, editors. A Dissection and Tissue Culture Manual of the Nervous System. New York: Alan R. Liss, Inc.; 1989. pp. 105-108.

9. Watson AA, Fairlie DP, Craik DJ. Solution structure of methionineoxidized amyloid beta-peptide (1-40). Does oxidation affect conformational switching? Biochemistry 1998; 37:12700-12706.

10. Hou L, Kang I, Marchant RE, Zagorski MG. Methionine 35 oxidation reduces fibril assembly of the amyloid abeta-(1-42) peptide of Alzheimer's disease. JBC 2002; 277:40173-40176.

11. Yatin SM, Varadarajan S, Link CD, Butterfield DA. In vitro and in vivo oxidative stress associated with Alzheimer's amyloid beta-peptide (1-42). Neurobiol Aging 1999; 20:325-330 (discussion 339-342).

12. Clementi ME, Misiti F. Substitution of methionine 35 inhibits apoptotic effects of Abeta(31-35) and Abeta(25-35) fragments of amyloid-beta protein in PC12 cells. Med Sci Monit 2005; 11:BR381-BR385.

13. Clementi ME, Pezzotti M, Orsini F, Sampaolese B, Mezzogori D, Grassi C, et al. Alzheimer's amyloid beta-peptide (1-42) induces cell death in human neuroblastoma via bax/bcl-2 ratio increase: an intriguing role for methionine 35. Biochem Biophys Res Commun 2006; 342:206-213.

14. Butterfield DA, Boyd-Kimball D. The critical role of methionine 35 in Alzheimer's amyloid beta-peptide (1-42)-induced oxidative stress and neurotoxicity. Biochim Biophys Acta 2005; 1703:149-156.

15. Curtain CC, Ali F, Volitakis I, Cherny RA, Norton RS, Beyreuther K, et al. Alzheimer's disease amyloid-beta binds copper and zinc to generate an allosterically ordered membrane-penetrating structure containing superoxide dismutase-like subunits. J Biol Chem 2001; 276:20466-20473.

16. Misiti F, Martorana GE, Nocca G, Di Stasio E, Giardina B, Clementi ME. Methionine 35 oxidation reduces toxic and pro-apoptotic effects of the amyloid beta-protein fragment (31-35) on isolated brain mitochondria. Neuroscience 2004; 126:297-303.

17. Tabner BJ, El-Agnaf OM, Turnbull S, German MJ, Paleologou KE, Hayashi $Y$, et al. Hydrogen peroxide is generated during the very early stages of aggregation of the amyloid peptides implicated in Alzheimer disease and familial British dementia. JBC 2005; 280:35789-35792.

18. Kriem B, Sponne I, Fifre A, Malaplate-Armand C, Lozac'h-Pillot K, Koziel V, et al. Cytosolic phospholipase A2 mediates neuronal apoptosis induced by soluble oligomers of the amyloid-beta peptide. FASEB J 2005; 19: 85-87.

19. Dringen R. Oxidative and antioxidative potential of brain microglial cells. Antioxid Redox Signal 2005; 7:1223-1233.

20. Itagaki S, McGeer PL, Akiyama H, Zhu S, Selkoe D. Relationship of microglia and astrocytes to amyloid deposits of Alzheimer disease. J Neuroimmunol 1989; 24:173-182.

21. Gabbita SP, Aksenov MY, Lovell MA, Markesbery WR. Decrease in peptide methionine sulfoxide reductase in Alzheimer's disease brain. J Neurochem 1999; 73:1660-1666.

22. Levine RL, Mosoni L, Berlett BS, Stadtman ER. Methionine residues as endogenous antioxidants in proteins. Proc Natl Acad Sci U S A 1996; 93:15036-15040 